\title{
EVALUASI KESESUAIAN LAHAN KUALITATIF DAN KUANTITATIF KAKAO DI KELOMPOK TANI KARYA SUBUR KECAMATAN PADANG CERMIN KABUPATEN PESAWARAN
}

\author{
Diyantri Agustina, Ali Kabul Mahi, Rusdi Evizal \& Tamaluddin Syam \\ Jurusan Agroteknologi, Fakultas Pertanian Universitas Lampung \\ Jl. Prof. Soemantri Brodjonegoro, No.1, Bandar Lampung 35145 \\ E-mail:imut.diyan@yahoo.com
}

\begin{abstract}
ABSTRAK
Tanaman Kakao (Theobroma cacao L.) merupakan salah satu tanaman perkebunan yang dibudidayakan oleh petani di Kabupaten Pesawaran. Budidaya tanaman kakao pada daerah tersebut cukup menguntungkan. Untuk itu diperlukan pengetahuan mengenai evaluasi lahan baik secara fisik (kualitatif) maupun ekonomi (kuantitatif). Penelitian dilakukan pada bulan April sampai dengan Mei 2012. Analisis tanah dilakukan di Laboratorium Jurusan Ilmu Tanah Fakultas Pertanian Universitas Lampung. Hasil penelitian menunjukkan bahwa lahan tanaman kakao di Desa Pesawaran Indah Kecamatan Padang Cermin Kabupaten Pesawaran berdasarkan potensi fisik lingkungan menurut kriteria Djaenuddin dkk. (2003), masuk kedalam kelas kesesuaian lahan sesuai marjinal dengan faktor pembatas $\mathrm{pH}(\mathrm{S} 3 \mathrm{nr}$ ), dan secara layak untuk dikembangkan dengan nilai $N P V$ sebesar Rp 474.995.222, Net B/C sebesar 2,36, IRR sebesar 48,5\%, dan BEP akan dicapai pada tahun ke-8, bulan ke-6, dan hari ke-15.
\end{abstract}

Kata kunci : Evaluasi kualitatif dan kuantitatif, kakao, kelayakan finansial

\section{PENDAHULUAN}

Tanaman kakao atau cokelat telah dikenal di Indonesia sejak tahun 1560, tetapi baru menjadi komoditi yang sangat penting sejak tahun 1951. Jenis yang pertama sekali ditanam di Indonesia adalah Criollo, yaitu di daerah Sulawesi Utara yang berasal dari Venezuela. Pada tahun 1888 diperkenalkan bahan tanaman Java Criollo asal Venezuela yang bahan dasarnya adalah kakao asal Sulawesi Utara tersebut, sebagai bahan tanaman tertua untuk mendapatkan bahan tanaman unggul. Sebelumnya pada tahun 1880, juga diperkenalkan bahan tanaman jenis forestero asal Venezeula untuk maksud yang sama (Tumpal,dkk., 2006).

Indonesia tercatat sebagai produsen ketiga terbesar di dunia untuk komoditas kakao. Luas area bertanaman kakao di Lampung adalah seluas 172.845 ha sedangkan hasil produksinya mencapai 153.112 ton. Untuk Kabupaten Pesawaran, luas pertanaman kakao seluas 5.470 ha dengan hasil produksi mencapai 5.363 ton (BPS, 2008).

Tanaman kakao dapat tumbuh subur dan berbuah di daerah tropis. Terletak antara $20^{\circ} \mathrm{LU}-20^{\circ} \mathrm{LS}$ dengan ketinggian 1-600 m dari permukaan laut, tetapi kadangkadang juga masih bisa tumbuh pada ketinggian $900 \mathrm{~m}$ dari permukaan laut. Tanaman kakao tidak tahan terhadap kekeringan yang panjang, curah hujan yang dibutuhkan adalah 1600-3000 mm per tahun. Suhu harian yang baik untuk pertumbuhan adalah $24-28^{\circ} \mathrm{C}$ dengan kelembaban $80 \%$. Tanaman ini berbunga sepanjang tahun. Jumlah bunga kakao mencapai 500-12000 bunga/ pohon/tahun, tetapi jumlah buah batang yang dihasilkan hanya sekitar $1 \%$. Penyeburkan bunga kakao dibantu oleh serangga Farcipomiya spp. (Susanto, 1992).

Evaluasi kesesuaian lahan merupakan penilaian kecocokan tipe lahan terhadap tipe penggunaan lahan spesifik. Tujuan evaluasi lahan itu sendiri yaitu memprediksi segala konsekuensi yang mungkin terjadi di dalam penggunaan lahan. Evaluasi lahan dapat dilakukan secara paralel yaitu evaluasi kualitatif dan kuantitatif dilakukan sacara bersamaan. Evaluasi kualitatif adalah avaluasi kesesuaian lahan dengan mempertimbangkan semua aspek yang menjadi pembatas dan dinyatakan dalam bentuk kualitatif yaitu sesuai, cukup sesuai, sesuai marjinal, dan tidak sesuai. Evaluasi kesesuaian lahan kuantitatif adalah menduga nilai produksi yang dihasilkan berdasarkan keuntungan atau kerugian penggunaan lahan tersebut (Mahi, 2005).

Tujuan evaluasi lahan adalah memprediksi segala konsekuensi yang mungkin terjadi bila ada perubahan penggunaan lahan (Mahi, 2004). Prediksi yang didasarkan atas kesesuaian lahan untuk berbagai bentuk produksi masukan dan pengelolaan yang diperlukan dengan konsekuensi perubahan-perubahan terhadap 
lingkungan akan memberi makna yang besar bagi keberlanjutan sumberdaya lahan. Konsekuensi tersebut termasuk kemungkinan kerusakan tanah oleh erosi pada lahan-lahan yang digunakan dengan tanpa memperhatikan teknik konservasi tanah.

Penelitian ini bertujuan untuk menilai kesesuaian lahan kualitatif tanaman kakao (Theobroma cacao L.) pada lahan Kelompok Tani Karya Subur Desa Pesawaran Indah Kecamatan Padang Cermin Kabupaten Pesawaran, berdasarkan kriteria Djaenuddin, dkk. (2003) dan menilai kesesuaian lahan kuantitatif dengan menganalisis nilai kelayakan finansial budidaya tanaman kakao (Theobroma cacao L.) pada lahan Kelompok Tani Karya Subur Desa Pesawaran Indah Kecamatan Padang Cermin Kabupaten Pesawaran.

\section{BAHAN DAN METODE}

Penelitian dilaksanakan pada lahan pertanaman kakao di Kelompok Tani Karya Subur Desa Pesawaran Indah Kecamatan Padang Cermin Kabupaten Pesawaran, dengan areal pertanaman kakao yang diteliti seluas 8 hektar. Penelitian ini dilaksanakan pada bulan April 2012 sampai Mei 2012.

Alat-alat yang digunakan antara lain yaitu bor tanah, GPS, buku munsell soil colour chart, dan alatalat laboratorium. Bahan-bahan yang digunakan dalam penelitian adalah contoh tanah yang diambil secara komposit dan bahan-bahan kimia yang digunakan untuk analisis tanah di laboratorium.

Metode yang digunakan pada penelitian ini adalah metode survei dengan pendekatan evaluasi lahan secara pararel, yaitu melakukan evaluasi kesesuaian lahan berdasarkan kriteria fisik Djaenuddin dkk. (2003), kriteria faktor produksi Dent dan Young (1981), dan analisis kelayakan finansial dilakukan dengan menghitung nilai Net Present Value (NPV), Net Benefit Cost Ratio (Net B/C), Internal Rate of Return (IRR) dan Break Event Point (BEP). Pelaksanaan Survei dilakukan terhadap yaitu: Tahan persiapan, pengumpulan data, dan analisis data. Kegiatan dalam tahapan persiapan ini meliputi studi pustaka untuk mengetahui kondisi umum di lokasi penelitian agar didapatkan gambaran umum tentang daerah penelitian, serta konsultasi dan pengumpulan bahan studi awal seperti data iklim, keadaan tanah, peta lokasi, dan laporan penelitian hasil setempat. Pada tahap ini dilakukan survei lapang secara kasar dan menentukan titik pengambilan contoh tanah yang mewakili secara keseluruhan berdasarkan keadaan lapang.
Pada tahap pengumpulan dan analisis data, data yang dikumpulkan dalam penelitian ini meliputi data fisik primer, data fisik sekunder, dan data ekonomi. Analisis kesesuaian lahan dilakukan dengan membandingkan potensi fisik lingkungan dengan persyaratan tumbuh tanaman kakao berdasarkan kriteria Djaenudin dkk. (2003). Untuk mengetahui kelayakan finansial usaha tani tanaman kakao dilakukan analisis sebagai berikut (Ibrahim, 2003).

Analisis Net Present Value (NPV) digunakan untuk menghitung selisih antara present value penerimaan (benefit) dengan present value dari biaya (cost). Secara matematis rumus untuk menghitung NPV adalah sebagai berikut:

$$
N P V=\sum_{i=l}^{n}(B-C) /(l+i)^{n}
$$

Keterangan :

$$
\begin{array}{ll}
\mathrm{B} & =\text { benefit (manfaat) } \\
\mathrm{C} & =\text { cost } \text { (biaya) } \\
\mathrm{i} & =\text { tingkat suku bunga bank yang berlaku } \\
\mathrm{n} & =\text { waktu }
\end{array}
$$

Kriteria investasi:

Bila NPV > 0, maka usaha layak untuk dilanjutkan Bila NPV $<0$, maka usaha tidak layak untuk dilanjutkan Bila NPV $=0$, usaha dalam keadaan break even point

Net Benefit Cost Ratio (Net B/C) merupakan nilai ratio perbandingan present value penerimaan bersih dengan present value biaya. Rumus matematikanya sebagai berikut:

Net $B / C$ Ratio $=\frac{\sum_{i=l}^{n}(B-C) /(l+i)^{n} \text { bernilai positif }}{\sum_{i=l}^{n}(B-C) /(l+i)^{n} \text { bernilainegatif }}$

Keterangan:

$\mathrm{B}=$ benefit (manfaat)

$\mathrm{C}=\operatorname{cost}$ (biaya)

$\mathrm{i}=$ tingkat suku bunga bank yang berlaku

$\mathrm{n}$ = waktu

Kriteria investasi:

Bila Net B/C > 1, maka usaha layak untuk dilanjutkan Bila Net $\mathrm{B} / \mathrm{C}<1$, maka usaha tidak layak untuk dilanjutkan

Bila Net $\mathrm{B} / \mathrm{C}=1$, usaha dalam keadaan break even point

Internal Rate of Return (IRR) digunakan untuk menunjukkan atau mencari suatu tingkat bunga yang menunjukkan jumlah nilai bersih sekarang netto (NVP) 
sama dengan seluruh ongkos investasi usahatani atau dengan kata lain tingkat bunga yang menghasilkan $N P V$ sama dengan nol $(N P V=0)$. Rumus yang digunakan adalah:

$$
I R R=i_{1}+\frac{N P V_{1}}{N P V_{1}-N P V_{2}}\left(i_{2}-i_{1}\right)
$$

Keterangan:

$\mathrm{i}^{1}=$ tingkat suku bunga yang menghasilkan $\mathrm{NPV}_{1}$

$\mathrm{i}^{2}=$ tingkat suku bunga yang menghasilkan $\mathrm{NPV}_{2}$

$\mathrm{NPV}_{1}=\mathrm{NPV}$ yang bernilai posotif

$\mathrm{NPV}_{2}=\mathrm{NPV}$ yang bernilai negatif

Kriteria investasi:

Bila IRR > tingkat suku bunga, maka usaha layak untuk dilanjutkan.

Bila IRR < tingkat suku bunga, usaha tidak layak untuk dilanjutkan.

Bila IRR = tingkat suku bunga, usaha dalam keadaan break even point.

Break Event Point (BEP) adalah titik pulang pokok dimana total revenue $($ total pendapatan $)=$ total cost (biaya total). Dilihat dari jangka waktu pelaksanaan sebuah proyek terjadinya titik pulang pokok atau $T R=T C$ tergantung lama arus penerimaan sebuah proyek dapat menutupi segala biaya operasi dan pemeliharaan beserta biaya modal lainnya. Rumus matematis yang digunakan untyuk menghitung $B E P$ yang menunjukkan waktu pengambilan total cost adalah sebagai berikut:

$$
B E P=\frac{T_{P-1}+\sum_{i=1}^{n} T c i-\sum_{i=1} \text { Biep }-1}{B p}
$$

Keterangan:

$$
\begin{aligned}
\text { BEP = } & \text { Break Even Point. } \\
\mathrm{T}_{\mathrm{P}-1}= & \text { Tahun sebelum terdapat BEP. } \\
\mathrm{T}_{\mathrm{ci}}= & \text { Jumlah total cost yang telah didiscont. } \\
\mathrm{B}_{\text {iep-1 }}= & \text { Jumlah benefit yang telah didiscont sebelum } \\
& \text { BEP. } \\
\mathrm{Bp}= & \text { Jumlah benefit pada saat BEP berada. }
\end{aligned}
$$

\section{HASIL DAN PEMBAHASAN}

Penilaian kesesuaian lahan kualitatif berdasarkan kriteria biofisik untuk tanaman kakao didasarkan pada kualitas dan karakteristik lahan yang berada di Kelompok Tani Karya Subur Desa Pesawaran Indah Kecamatan Padang Cermin Kabupaten Pesawaran yang dibandingkan dengan persyaratan tumbuh tanaman kakao berdasarkan kriteria Djaenuddin dkk. (2003) termasuk kedalam kelas kesesuaian lahan sesuai marjinal dengan factor pembatas $\mathrm{pH}$ (S3nr). Faktor pembatas ini sangat mempengaruhi hasil produksi tanaman kakao. Tanaman kakao dapat tumbuh baik pada pH 6,0 - 7,0 (Djaenuddin, 2003), namun pada lahan penelitian memiliki $\mathrm{pH}$ lebih rendah, sehingga hasil produksinya tidak mencapai hasil produksi yang optimal. Faktor pembatas ini dapat diperbaiki dengan cara dilakukannya pengapuran pada lahan penelitian dengan menambahkan kapur sesuai kebutuhan lahan tersebut, sehingga $\mathrm{pH}$ pada lahan penelitian menjadi cukup sesuai. Data selengkapnya tertera pada Tabel 1 .

Penilaian kesesuaian lahan berdasarkan faktor produksi didasarkan atas hasil produksi tanaman kakao di lapangan selama 5 tahun saat produksi mencapai puncak tertinggi dan dibandingkan dengan potensi produksi tanaman kakao. Dari hasil perbandingan tersebut, maka didapat persen (\%) produksi tanaman kakao sebesar 45,53\%. Berdasarkan analisis kesesuaian lahan menurut Dent dan Young (1981), maka termasuk dalam kelas kesesuaian lahan cukup sesuai (S2). Data selengkapnya tertera pada Tabel 2.

Pada usaha tani kakao tenaga kerja yang digunakan pada tahun ke-1 sebanyak 140 HKP, tahun ke-2 sebanyak 40 HKP, tahun ke-3 sebanyak 172 HKP, tahun ke-4 sampai tahun ke-8 sebanyak 142, tahun ke9 sampai tahun ke-19 sebanyak $150 \mathrm{HKP}$, dan pada tahun ke-20 sampai tahun ke-25sebanyak 142 HKP.

Sarana Produksi yang diperlukan petani per hektar yaitu 625 bibit kakao, TSP $50 \mathrm{~kg}$, Urea $100 \mathrm{~kg}$, dan KCl $50 \mathrm{~kg}$. Sarana pendukung lainnya yaitu alat-alat pertanian yang digunakan dalam pemeliharaan tanaman kakao sampai dengan panen. Pada tahun 2012 produksi mencapai $1.039 \mathrm{~kg}$ dengan harga 16.256 per kg dengan pendapatan 16.889.984,dengan biaya usaha tani sebesar 4.259.700 sehingga keuntungan yang didapat sebesar 12.623.084 per hektar. Dari hasil perhitungan didapatkan nilai-nilai:

Net Present Value (NPV) merupakan selisih nilai sekarang pendapatan dengan nilai sekarang investasi selama umur ekonomis tanaman kakao. Tingkat suku bunga yang digunakan adalah $15 \%$ yang merupakan suku bunga yang berlaku di masyarakat saat ini. Berdasarkan hasil pengolahan data, diperoleh NPV sebesar Rp. 474.995.222, menunjukkan NPV > 0. Ini berarti usaha perkebunan kakao di Kelompok Tani Karya Subur Desa Pesawaran Indah Kecamatan Padang Cermin Kabupaten Pesawaran layak untuk dikembangkan. Hasil perhitungan NPV menunjukkan bahwa selama 25 tahun usaha perkebunan kakao ini tidak akan mengalami kerugian kecuali disebabkan oleh faktor-faktor alam. 
Tabel 1. Penilaian kelas kesesuaian lahan tanaman kakao pada lahan penelitian.

\begin{tabular}{|c|c|c|}
\hline $\begin{array}{c}\text { Persyaratan penggunaan } \\
\text { (Kualitas/karakteristik lahan) }\end{array}$ & Nilai & Kelas kesesuaian lahan \\
\hline $\begin{array}{l}\text { Temperatur }(\mathrm{tc}) \\
\text { Suhu tahunan rata-rata }\left({ }^{\circ} \mathrm{C}\right)\end{array}$ & 26,7 & $\mathrm{~S} 1$ \\
\hline $\begin{array}{l}\text { Keters ediaan air (wa) } \\
\text { Curah hujan (mm) }\end{array}$ & 2047 & S1 \\
\hline $\begin{array}{l}\text { Keters ediaan oksigen (oa) } \\
\text { Drainase }\end{array}$ & Baik & S1 \\
\hline $\begin{array}{l}\text { Media perakaran }(\mathrm{rc}) \\
\text { 1. Tekstur tanah } \\
\text { 2. Bahan kasar }(\%) \\
\text { 3. Kedalaman tanah }(\mathrm{cm})\end{array}$ & $\begin{array}{c}\text { Agak halus } \\
0 \\
120\end{array}$ & $\begin{array}{l}\text { S1 } \\
\text { S1 } \\
\text { S1 }\end{array}$ \\
\hline $\begin{array}{l}\text { Retensi hara }(\mathrm{nr}) \\
\text { 1. KTK liat }\left(\mathrm{cmol}_{d} / \mathrm{kg}\right) \\
\text { 2. Kejenuhan basa }(\%) \\
\text { 3. pH tanah }\left(\mathrm{H}_{2} \mathrm{O}\right) \\
\text { 4. C-organik }(\%)\end{array}$ & $\begin{array}{c}17,16 \\
40,385 \\
5,115 \\
1,175\end{array}$ & $\begin{array}{l}\text { S1 } \\
\text { S1 } \\
\text { S3 } \\
\text { S2 }\end{array}$ \\
\hline $\begin{array}{l}\text { Bahaya erosi (eh) } \\
\text { 1. Lereng (\%) } \\
\text { 2. Bahaya erosi }\end{array}$ & $\begin{array}{c}7,75 \\
\text { Sangat ringan }\end{array}$ & $\begin{array}{l}\text { S1 } \\
\text { S1 }\end{array}$ \\
\hline $\begin{array}{l}\text { Bahaya banjir (fh) } \\
\text { Genangan }\end{array}$ & F0 & $\mathrm{S} 1$ \\
\hline $\begin{array}{l}\text { Persiapan lahan (lp) } \\
\text { 1. Batuan permukaan }(\%) \\
\text { 2. Singkapan batuan }(\%)\end{array}$ & $\begin{array}{l}0 \\
0\end{array}$ & $\begin{array}{l}\text { S1 } \\
\text { S1 }\end{array}$ \\
\hline
\end{tabular}

Sumber: Hasil analisis (2012)

Tabel 2. Penilaian kelas kesesuaian lahan berdasarkan produksi.

\begin{tabular}{cccccccc}
\hline No & $\begin{array}{c}\text { Tahun } \\
\text { Produksi }\end{array}$ & $\begin{array}{c}\text { Umur } \\
\text { (tahun) }\end{array}$ & $\begin{array}{c}\text { Produksi } \\
\text { di lapang } \\
(\mathrm{kg} / 8 \mathrm{Ha})\end{array}$ & $\begin{array}{c}\text { Produksi } \\
\text { di lapang } \\
\text { (kg/Ha) }\end{array}$ & $\begin{array}{c}\text { Potensi } \\
\text { produksi } \\
(\mathrm{kg})\end{array}$ & $\begin{array}{c}\text { \% Hasil terhadap } \\
\text { produksi } \\
(\mathrm{kg})\end{array}$ & $\begin{array}{c}\text { Kelas } \\
\text { kesesuaian } \\
\text { lahan }\end{array}$ \\
\hline 1 & 2002 & 11 & 10.544 & 1.318 & & 43,93 & \\
2 & 2003 & 12 & 10.884 & 1.360 & & 45,53 & \\
3 & 2004 & 13 & 11.144 & 1.393 & & 46,64 & \\
4 & 2005 & 14 & 11.072 & 1.384 & & 46,13 & \\
5 & 2006 & 15 & 10.912 & 1.364 & & 25,46 & \\
\hline & Jumlah & 54.556 & 6.819 & & 45,53 & $\mathrm{~S} 2$ \\
\hline
\end{tabular}

Sumber: Pengolahan data primer (2012) 
Net Benefit / Cost Ratio (Net B/C ratio) adalah perbandingan antara nilai manfaat bersih dengan biaya bersih yang diperhitungkan nilainya saat ini. Net B/C yang diperoleh dari hasil pengolahan data tahun pertama sampai dengan tahun ke-25 adalah 2,36, menunjukkan Net $B / C>1$ berarti usaha perkebunan kakao di Kelompok Tani Karya Subur Desa Pesawaran Indah Kecamatan Padang Cermin Kabupaten Pesawaran layak untuk dikembangkan.

Internal Rate of Return (IRR) adalah suatu tingkat bunga dimana nilai sekarang pendapatan sama dengan nilai sekarang investasi. Berdasarkan hasil pengolahan data diperoleh nilai IRR sebesar 48,5\%. Hal ini menyatakan bahwa usaha perkebunan kakao di Kelompok Tani Karya Subur Desa Pesawaran Indah Kecamatan Padang Cermin Kabupaten Pesawaran sampai tingkat suku bunga yang berlaku $15 \%$ masih layak untuk dikembangkan. Nilai IRR adalah sebesar 48,5\% lebih besar dari tingkat bunga yang berlaku di masyarakat yaitu $15 \%$ maka Kelompok Tani Karya Subur Desa Pesawaran Indah Kecamatan Padang Cermin Kabupaten Pesawaran tidak akan mengalami kerugian.

Break Even Point (BEP) atau titik impas dimana $T R=T C($ Total Pendapatan $=$ Total Biaya $)$. Dari hasil perhitungan selama umur ekonomis (25 tahun) maka diperoleh hasil bahwa usaha perkebunan kakao di Kelompok Tani Karya Subur Desa Pesawaran Indah Kecamatan Padang Cermin Kabupaten Pesawaran akan mencapai titik impas atau dengan kata lain, pengembalian biaya modal dan biaya-biaya lainnya akan dicapai selama 8 tahun 6 bulan 15 hari.

\section{KESIMPULAN}

Berdasarkan hasil penelitian yang telah dilakukan maka dapat disimpulkan bahwa lahan di Desa Pesawaran Indah Kecamatan Padang Cermin Kabupaten Pesawaran tergolong dalam kesesuaian lahan sesuai marjinal untuk tanaman kakao dengan faktor pembatas retensi hara (pH S3nr). Dari hasil perbandingan, maka didapat persen (\%) produksi tanaman kakao sebesar 45,53\%. Berdasarkan analisis kesesuaian lahan menurut Dent dan Young (1981), termasuk dalam kelas kesesuaian lahan cukup sesuai (S2).
Berdasarkan hasil analisis finansial usaha perkebunan tanaman kakao di Kelompok Tani Karya Subur Desa Pesawaran Indah Kecamatan Padang Cermin Kabupaten Pesawaran seluas 8 hektar selama 25 tahun layak untuk dikembangkan dengan NPV = Rp 474.995.222, Net $\mathrm{B} / \mathrm{C}$ ratio $=2,36, \mathrm{IRR}=48,5 \%$ per tahun, dan $\mathrm{BEP}=8$ tahun 6 bulan 15 hari.

\section{DAFTAR PUSTAKA}

Biro Pusat Statistik. 2008. Lampung Dalam Angka. Biro Pusat Statistik. Bandar Lampung.

Dent, D. dan Young. 1981. Soil Survey and Evaluation. George Allen and Unwim. London. 279 pp.

Djaenuddin, D., H. Marwan, H. Subagyo, dan A. Hidayat. 2003. Petunjuk Teknis Evaluasi Lahan Untuk Komoditas Pertanian. Departemen Pertanian. $154 \mathrm{hlm}$.

Ibrahim, Y. 2003. Studi Kelayakan Bisnis. PT Rineka Cipta. Jakarta. 249 hlm.

Mahi, A.K. 2004. Survei Tanah dan Evaluasi Lahan (Diktat Kuliah). Jurusan Ilmu Tanah Fakultas Pertanian Universitas Lampung. Bandar Lampung. $184 \mathrm{hlm}$.

Mahi, A.K.2005. Evaluasi dan Perencanaan Penggunaan Lahan. (Diktat, tidak dipublikasikan). Fakultas Pertanian Universitas Lampung. Bandar Lampung. $240 \mathrm{hlm}$.

Riyadi. 2000. Budidaya Kakao. Penerbit Penebar Swadaya. Jakarta. $94 \mathrm{hlm}$.

Siregar, Tumpal H.S., S. Riyadi, L. Nur'aeini. 2000. Budidaya Pengelolahan dan Pemasaran Coklat. Penebar Swadaya. Jakarta. 170 hlm.

Susanto, H. 1992. Kakao (Budidaya, Pengolahan Hasil dan Aspek Ekonominya). Kanisius. Yogyakarta. $130 \mathrm{hlm}$. 